\title{
MOTHERS AND FATHERS FACE TO FACE MEDIA EXPOSURE OF THEIR CHILDREN IN THE TIME OF LOCKDOWN IN THE CZECH REPUBLIC
}

\author{
Petra Ambrožová ${ }^{1}$, Iva Junová ${ }^{2}$, Jiřina Krejčová ${ }^{3}$, Leona Stašová ${ }^{4 \star}$ \\ ${ }^{1}$ Ph.D, Faculty of Education, University of Hradec Králové, Czech Republic, \\ petra.ambrozova@uhk.cz \\ ${ }^{2} \mathrm{Ph} . \mathrm{D}$, Faculty of Education, University of Hradec Králové, Czech Republic, iva.junova@uhk.cz \\ ${ }^{3} \mathrm{Bc}$, Faculty of Education, University of Hradec Králové, Czech Republic, jirina.krejcova@uhk.cz \\ ${ }^{4}$ Ph.D., Faculty of Education, University of Hradec Králové, Czech Republic, \\ leona.stasova@uhk.cz \\ ${ }^{*}$ Corresponding Author
}

\begin{abstract}
Coronavirus has had a very significant impact on many areas of human life. The pandemic affected not only adults but also children. Children, who have been gradually moving into cyberspace in the last few years, are now much more supported in the use of the media, for example in the field of education (in the Czech Republic, virtually all schooling has moved to the Internet and television) and in leisure areas (some radio stations also responded to the lockdown). The paper focuses on mapping the attitudes and experiences of parents of children under 15 years of age to the use of media by their children during the lockdown in the Czech Republic and the differences in the attitudes of fathers and mothers. It presents the results of a study carried out in the form of a questionnaire during the first wave of the COVID-19 pandemic, when parents were unprepared for government action and shows, that women bore a greater part of the responsibility for parental support in the area of media use during the period of online learning in Czech families.
\end{abstract}

Keywords: Media, Parents, Children, Lockdown.

\section{INTRODUCTION}

The world is going through difficult times. "Worldwide, the coronavirus disease 2019 (COVID-19) pandemic has generated significant worry, uncertainty, anxiety, sadness, and loneliness." (Marchetti, et al., 2020). The situation has been rather challenging for parents, in particular. In a relatively short time, the parents had to assume several roles which had previously been fulfilled by other institutions. They became teachers of several school subjects, IT specialists offering support in online education and they also had to provide the meals and manage their children's free time. All of this had to be arranged under special circumstances, in limited space and often in addition to the parents' jobs. While researchers in the Czech Republic and abroad has focused primarily the high stress levels in healthcare workers, policemen, firefighters and teachers or patients combatting depression or fear of the disease, the results of research conducted by Marchetti et al. (2020) showed that $17 \%$ out of the 1223 parents involved in the survey had serious symptoms of exhaustion connected with the lockdown. Moreover, little information has been collected on the effects of lockdown on families with children, parental care and approach to media.

This is why our contribution examines the experience of mothers and fathers with the lockdown in the Czech Republic and the support and control of their children's use of media in online education. The project is comparatively exceptional, firstly in its focus on the first COVID-19 wave (spring 2020) and secondly in analysing the view of mothers as well as fathers. According to Anmari, Schoenebeck (2018), academic research tends to favour mothers' views, as a rule, accidentally placing mothers in the role of primary caregivers, which produces biased results. The authors of this text perceive both parents as equal partners in the education of their child, including media education. Several studies point out that the fathers' 
contribution to the prosperity of the child is as significant as the mothers'. Fatherly care contributes to the social competence of the child and his/her successful socialisation. It also has a significant effect on the development of cognitive abilities of the child. Furthermore, it has been shown that the involvement of fathers in education decreases aggression in boys and fosters emotional ease in girls (e.g. Pavlát, 2008, Yoder et al., 2016, Torres et al., 2014). The underrepresentation in the research of the fathers' view of their children's use of media is also mentioned in Tang et al. (2018), who claims that „the majority of these studies that did include fathers combined information across parents rather than distinguish mothers from fathers". At the same time, it is obvious that mothers and fathers have different attitudes e.g. to media education and they also use media in different ways and set different examples for their children (compare Van Den Bulck, Van Den Bergh, 2000). In recent years, the number of fathers working from home and fathers on paternity leave has been increasing, although there still are certain imbalances (see Anmari, Schoenebeck, 2018). The lockdown period required more work from home and more time from children (which concerned both mothers and fathers) because the Czech government closed all schools, restricted freedom of movement and made home office compulsory, in order to prevent the spread of the virus.

As a result, the lockdown period in the Czech Republic between March and May 2020 confronted the parents with new and unpredictable situations, in which they had to cope with many difficult moments in their family lives. At the family level, parents are being called to cope with the additional stress and emotional difficulties caused by school closures and children's confinement at home (Marchetti, 2020). „Key factors influencing family stress include balancing work with childcare/homeschooling and financial instability." (Caroll et al., 2020)

School closure and the switch to online learning were (and still are, during the second wave of the pandemic) accompanied by the use of media for educational purposes, which forced the parents to deal with family media education. Children's media consumption has been significantly increasing over recent years, which was proved, among others, by Tang et al. (2018) - from 2011 to 2013 the percentage of 2 to 4 -year-old children using mobile media devices in the United States increased from 39 to $80 \%$. Caroll et al. (2020) state that "screen time during lockdown increased among $74 \%$ of mothers, $61 \%$ of fathers, and $87 \%$ of children and physical activity decreased among $59 \%$ of mothers, $52 \%$ of fathers, and $52 \%$ of children ". The amount of time which children spend with media increased further because of online learning and restrictions affecting organised leisure activities.

New challenges associated with high demands on parents during the pandemic can also result in so-called parental burnout (see Marchetti, 2020, Roskam et al., 2017). It is important to know how the parents responded to the difficult situation and how they coped with the increased need for child care and regulation of children's media activities as well as the compensation of the unilateral load caused by media use.

\section{METHODOLOGY}

The research survey is based on various basic theoretical frameworks, which we had decided to prove on parents' sample from the Czech Republic. We have mainly focused on:

1. Increasing number of time children spend with media as a result of spring lockdown during COVID19 pandemic in the Czech Republic.

As Fisher (2020) states, the time children at the age of 6-12 years spent has increased at least by $50 \%$ concerning media use during the coronavirus period. The core of our theoretical concept lies in increasing time of children's media use and exposure. Within international context was found that e.g. American children say they used screen devices either a lot more (at least $50 \%$ more), twice as much, or for what felt like "most of the day" during the coronavirus pandemic (Fisher, 2020).

2. Series of parental questions, how to deal with new - coronovirus - situation in terms of the amount of time children spend with media.

Fisher (2020) mentions that "Parents were already struggling to limit screen time for kids when they were in school, let alone trying to pull them away from their devices while they are forced to stay home away from their friends, peers and regular activities."

3. Parent strategies which are applied in order to reduce the amount of time children spend with media.

Goldschmidt (2020) states, that families seem to be spending more time together, walking, biking, and completing school work, playing together, making crafts, listening to music or watching TV together.

4. Gender differences in parental mediation strategies, which had been studied mainly in terms of 
general view, not in the connection of the current coronavirus situation.

Duek and Moguillansky (2020) found that the activities involved in parental mediation had been gendered in complex ways: there were certain tasks perceived to be more typical of fathers and others supposed to be the domain of the mothers.

The respondents in our survey were families with at least one child aged 6 to 15 years. The families were chosen by quota selection, considering the age of the children and parents' education level. The intention was to achieve maximal diversity of the sample as to the age of children and parents' education level.

The quantitative data were collected by self-constructed questionnaire prepared separately for parents and children. Both questionnaires focused on the same topics and used questions and scales taking into account specific situation of parents and children and their perception of the family situation. Our questionnaires consisted from three main parts; firstly, identifying characteristics of respondents and their families, secondly, detecting respondents' usual media habits, attitudes and experience and thirdly, describing pandemic/lockdown specifics in relation to media use and homeschooling. Furthermore, prepared questionnaire had been piloted and items were revised upon reviewing its'results. It is important to note, that this paper focuses mainly on parents' answers and third part of these questionnaires in relation to parents' characteristics.

Both parents were asked to fill in the questionnaire unless only one parent was living in the family, in which case he or she was our only respondent. As for research ethics, the researcher first discussed the possibility to participate in the survey with the family. After obtaining their verbal consent with participation, the questionnaires were handed over. The respondents were assured of the anonymity of the survey and asked to provide true and complete answers. The researcher also explained the purpose of the survey and its importance to the respondents.

In total, 191 parents of children aged 6 to 15 participated in our survey. There were 77 fathers and 114 mothers, i.e. $40 \%$ of fathers and $60 \%$ of mothers. This ratio reflects the ratio of single-parent families in the research sample. The table below presents an overview of how the data of this research look like; it gives a computed detail of selected variables.

Table 1. Descriptive Statistics

\begin{tabular}{|l|c|c|c|c|}
\hline & N valid & N missing & Median & Mode \\
\hline Age & 191 & 0 & 3,0 & 2 \\
\hline Education & 191 & 0 & 3,0 & 3 \\
\hline $\begin{array}{l}\text { Covid parents'work } \\
\text { Parents'time for } \\
\text { children }\end{array}$ & 189 & 2 & --- & 3 \\
\hline $\begin{array}{l}\text { Parental help } \\
\text { Changing rules }\end{array}$ & 184 & 1 & --- & 2 \\
\hline
\end{tabular}

Table 2 shows the stratification of the sample by age into four intervals. Most of the parents (56\%) were in the category 40-49 years. Almost one third of the parents were aged 30-39 years. Only 8\% of parents were over 50 and most of them were men. The least represented category was that of the youngest parents (up to 29 years) with less than $5 \%$ of respondents.

Table 2. Sample structure by age

\begin{tabular}{|l|c|c|c|c|c|c|}
\hline Age & N & \% & Men & $\%$ & Women & $\%$ \\
\hline $\mathbf{2 0 - 2 9}$ & 9 & 4.7 & 3 & 3.9 & 6 & 5.3 \\
\hline $\mathbf{3 0 - 3 9}$ & 60 & 31.4 & 17 & 22.1 & 43 & 37.7 \\
\hline $\mathbf{4 0 - 4 9}$ & 107 & 56.0 & 44 & 57.1 & 63 & 55.3 \\
\hline $\mathbf{5 0 +}$ & 15 & 7.9 & 13 & 16.9 & 2 & 1.8 \\
\hline Total & 191 & 100.0 & 77 & 100.0 & 114 & 100.0 \\
\hline
\end{tabular}


Table 3 shows that our sample comprised $31.4 \%$ respondents with primary education or apprenticeship certificate, one third of respondents had secondary education with A-level and another third had attended college or university. There were more women than men with university education (the difference was $7 \%$ ).

Table 3. Sample structure by education level

\begin{tabular}{|l|c|c|c|c|c|c|}
\hline Education level & $\mathbf{N}$ & $\%$ & Men & $\%$ & Women & $\%$ \\
\hline Primary & 5 & 2.6 & 1 & 1.3 & 4 & 3.5 \\
\hline $\begin{array}{l}\text { Apprenticeship } \\
\text { certificate }\end{array}$ & 55 & 28.8 & 30 & 39.0 & 25 & 21.9 \\
\hline $\begin{array}{l}\text { Secondary with } \\
\text { "A-level" }\end{array}$ & 64 & 33.5 & 24 & 31.2 & 40 & 35.1 \\
\hline College & 11 & 5.8 & 3 & 3.9 & 8 & 7.0 \\
\hline University & 56 & 29.3 & 19 & 24.7 & 37 & 32.5 \\
\hline Total & 191 & 100.0 & 77 & 100.0 & 114 & 100.0 \\
\hline
\end{tabular}

As for the structure of the sample by employment status, $75 \%$ of respondents were employees, nearly $17 \%$ were self-employed, a small group $(4.7 \%)$ were on maternity/paternity leave and $2.1 \%$ were unemployed. Out of the total number of parents, $28.3 \%$ had only one child, more than a half $(54.4 \%)$ has two children, $12.6 \%$ had three and $4.7 \%$ had four or more children. The families involved in the survey lived in localities of different size.

\section{RESULTS}

The data obtained through the questionnaire survey were subject to quantitative analysis in the statistical software SPSS. The questions discussed in this contribution concentrate on the parents' dealing with the lockdown situation, the time spent with children and support for children, the time spent by children with media and possible change of rules of media use and also on leisure activities favoured by the parents in the examined period.

The first question aiming at the situation of families during the lockdown in spring 2020 concerned the effects of lockdown on parents' working conditions. The results are presented in Table 4 below.

Table 4. The effect of the 2020 spring lockdown on parents' working conditions

\begin{tabular}{|l|c|c|c|c|c|c|}
\hline Parents' work & N & $\%$ & Men & $\%$ & Women & $\%$ \\
\hline $\begin{array}{l}\text { At home with children on state } \\
\text { allowance }\end{array}$ & 28 & 14.8 & 3 & 3.9 & 25 & 22.1 \\
\hline Home office & 47 & 24.9 & 12 & 15.8 & 35 & 31.0 \\
\hline At work, as usual & 59 & 31.2 & 37 & 48.7 & 22 & 19.5 \\
\hline At work, but less time than usual & 26 & 13.8 & 11 & 14.5 & 15 & 13.3 \\
\hline At work, but more time as usual & 9 & 4.8 & 6 & 7.9 & 3 & 2.7 \\
\hline Other & 20 & 10.6 & 7 & 9.2 & 13 & 11.5 \\
\hline Total & 189 & 100.0 & 76 & 100.0 & 113 & 100.0 \\
\hline
\end{tabular}

The most numerous group were respondents (31\%) who answered that they went to work, as usual, a quarter of respondents worked from a home office. Almost $15 \%$ stayed home on state allowance. Almost $14 \%$ were at their workplace but they worked less than usual and slightly less than $5 \%$ stated that they worked more than usual.

This question was associated with clear differences between mothers and fathers. The most frequent answer of fathers (almost 50\%) was that they went to work as usual. A little less than $16 \%$ worked from a home office. $15 \%$ of men went to work less than usual, on contrary $8 \%$ worked more than usual. There were only three men who stayed home with the children. The most common answer of mothers was that they worked from a home office (31\%). $22 \%$ of mothers stayed home with the children and a little less than $20 \%$ went to work as usual. $13 \%$ of women spend less time than usual at work and only three worked more than usual.

As for a comparison of the two genders, there were only approximately $4 \%$ of men who stayed home with the children but the corresponding number for women was roughly one fifth (22\%). Also, women worked 
from home office (31\%) significantly more often than men (15\%). Almost one-half of male respondents stated that they went to work as usual, while the same number for women was only $20 \%$. Contrarily, there were slightly more men than women who stated that they worked more than usual ( $8 \%$ of men and $3 \%$ of women). The differences between men and women were statistically significant.

One of the long-term problems connected with the current lifestyle in the Western world is a lack of parents' time for their children. Therefore, our next question continues the previous one and asks about the parents' subjective view of the amount of time which they had for their children during the lockdown.

Covid-19 brought about a positive change here because a vast majority of parents participating in our research (87\%) stated that they had the same or a greater amount of time for their children during the lockdown. There were only $13 \%$ of parents who admitted that they had less time for their children. If we examine the dependence of answers on gender (Fig. 1), we can see that more than one-half of the mothers claimed to have had more time for their children than usual. This number is presumably connected with the higher percentage of mothers who stayed home with the children or worked from the home office. As for fathers, only $29 \%$ of them said that they had more parent-child time. On the other hand, it is also interesting to observe that women claimed to perceive a decrease in parent-child time more often than men. Almost $15 \%$ of mothers stated that they had less time for their children than usual, while the same number for men was only $9 \%$.

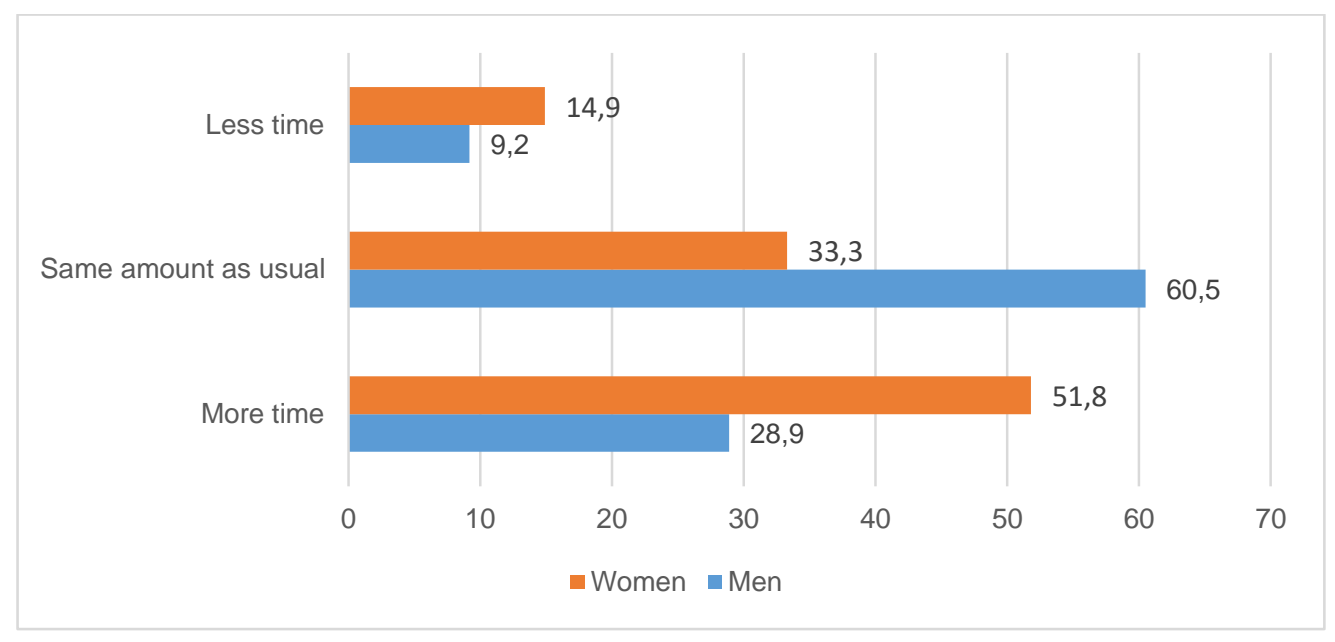

Fig. 1. The amount of time which parents had for their children during the lockdown in spring 2020 (in \%)

Moreover, there was a significant correlation between work mode during lockdown and parent-child time. The respondents who stayed home with the children or worked from home office considerably more often stated that they had more time for their children.

Another question was aimed to figure out how much time the children were spending with electronic media, according to their parents' estimation. The answers were consistent with respect to both the gender and the parents' occupation during the lockdown. The overall results are presented in Fig.2.

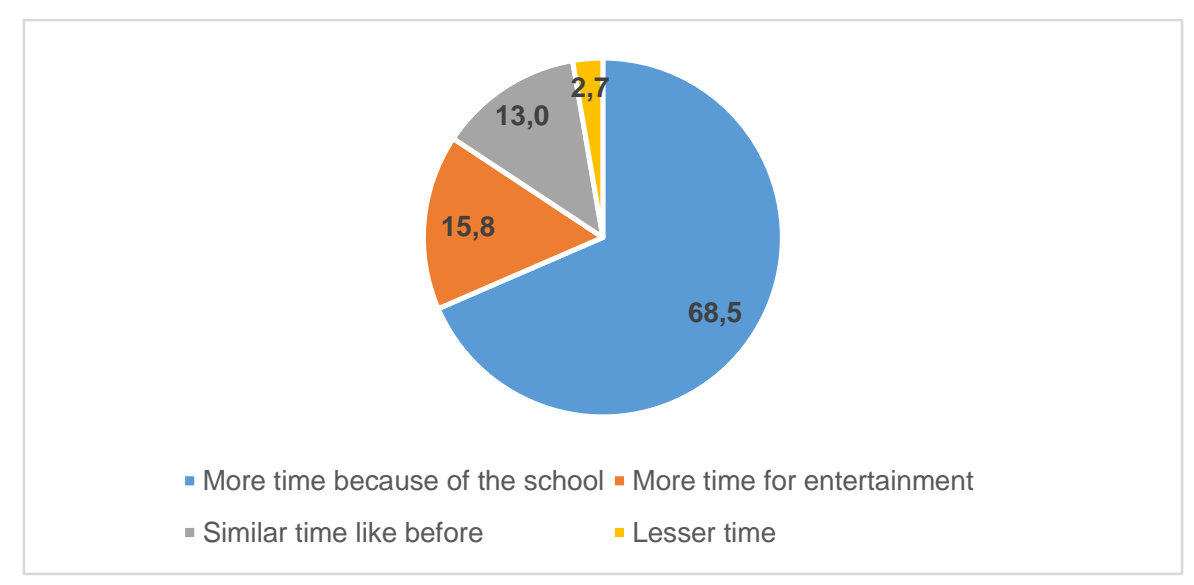

Fig. 2. Time children spent with electronic media during the 2020 spring lockdown according to their parents' estimation (\% of parents' answers) 
From Fig. 2 it becomes apparent that according to $84 \%$ of parents, their children were spending more time with electronic media during the lockdown. $2 / 3$ of parents have identified on-line school education as the main reason for the increased time their children spent with electronic media. Approximately $16 \%$ of parent assume that their children spent more time with e-media for entertainment purposes. Only less than $16 \%$ of parents assume that during the spring lockdown, their children were spending the same amount of or even lesser time with e-media than before.

The lockdown of schools resulted in the increased demands not only on children but also their parents. The parents needed to help their children with on-line education and homework. The frequency of the help the parents were providing their children was examined with the next question (Table 5).

Table 5. Frequency of the parental help to children with school duties during the 2020 spring lockdown

\begin{tabular}{|l|c|c|c|c|c|c|}
\hline The parental help & N & $\%$ & Men & $\%$ & Women & $\%$ \\
\hline Yes, every day & 79 & 42.9 & 19 & 26.0 & 60 & $5 ., 1$ \\
\hline Yes, several times per a week & 48 & 26.1 & 21 & 28.8 & 27 & 24.3 \\
\hline Yes, approx. one time per a week & 16 & 8.7 & 9 & 12.3 & 7 & 6.3 \\
\hline No, I had no time & 10 & 5.4 & 7 & 9.6 & 3 & 2.7 \\
\hline $\begin{array}{l}\text { No, the child was self-sufficient } \\
\text { with this }\end{array}$ & 16 & 8.7 & 8 & 11.0 & 8 & 7.2 \\
\hline Somebody other was helping & 15 & 8.2 & 9 & 12.3 & 6 & 5.4 \\
\hline Together & 184 & 100 & 73 & 100 & 111 & 100 \\
\hline
\end{tabular}

Together $43 \%$ of parents answered that they needed to help their children with on-line education and preparation for it every day during the spring lockdown. $26 \%$ of parents were helping their children several times per week. As was already suggested in Table 3, mothers were more often to stay at home with their children and were also more often helping them. Table 5 confirms that mothers more often assist their children in their school and education duties. $78 \%$ of mothers were helping their children every day, in contrast to just $55 \%$ of fathers. $1 / 3$ of males answered that they had no time for their children, or that the children were self-sufficient, of that somebody other was helping them. In contrast, only $16 \%$ or women selected these answers.

The question of how families were spending their free time during the spring lockdown returned some interesting answers. The responded should select max 3 options or write down their own answer. Table 6 presents the results in descending order according to the frequency. With respect to that respondents could select multiple options, the number of respondents who selected the given option is listed in the table. The percentage proportion of figures are calculated for individual entries out of the total number of respondents. Therefore, the sum of the percentage figures does not return $100 \%$.

Table 6. Ways of spending the family free time during the 2020 spring lockdown ( $N=191$ respondents)

\begin{tabular}{|l|c|}
\hline $\begin{array}{l}\text { Way of spending the free } \\
\text { time }\end{array}$ & Answers in \% \\
\hline In the garden & 64.9 \\
\hline Walks & 60.2 \\
\hline Board games & 29.3 \\
\hline Cycling, roller skating & 27.2 \\
\hline TV & 25.1 \\
\hline Drawing, manual activities & 16.2 \\
\hline Other & 7.3 \\
\hline PC games & 4.7 \\
\hline
\end{tabular}


The question for Table 6 has its limitations. The term "free time" itself is problematic and can be interpreted subjectively. This is particularly true during the lockdown, when different family members can perceive differently, what is free time to them. For this reason, we chose options typical for free time activities of both adults and children.

Individual activities are listed in the descending order according to the frequency of answers. It becomes apparent that the first two ranks are occupied by the outside activities They are twice as much represented among the answer than the following indoor activities. Among those, board games occupy the highest rank, selected by almost $1 / 3$ of respondents. Then, another outdoor activity follows: Cycling or roller skating. $1 / 4$ of respondents were watching TV together with their children. $16 \%$ of families got engaged in art or manual activities. Playing PC games has turned out to be the last frequent activity.

It becomes clear that the parents were attempting to fill their children's free time during the lockdown with activities, on which could the children and their parents participate together. Only two of the listed options were related to media - watching TV and playing PC games. While $25 \%$ of parents were watching TV in their free time, only less than $5 \%$ were playing PC games. The explanation is at hand that while the parents perceive watching the TV as the opportunity to relax and have fun together, they probably do not consider playing PC games as a meaningful way of spending their free time. The question remains, whether the results would look similar in times without the lockdown.

Comparing the results gender-wise, mothers are more active with a majority of the activities than fathers. More often are the mothers playing board games (33.3\% vs $23.4 \%)$, drawing with their children $(17.5 \%$ vs $14.3 \%)$, but are also more active when it comes to outdoor activities. Mothers more often take their children for a walk $(65.8 \%$ vs $51.9 \%)$ or to the garden $(66.7 \%$ vs $62.3 \%)$. The fathers prefer sporting outdoor activities, specifically cycling and roller skating (33.8\% vs $21.1 \%)$. At the same time, fathers more often selected watching TV as their way of spending free time (31.2\% vs $21.1 \%)$.

With the next question, we were aiming to figure out, if the family rules for using the media changed during the COVID lockdown. The results are shown in Table 7.

Table 7: Changing rules for using the media in families during the lockdown

\begin{tabular}{|l|c|c|c|}
\hline Change of rules & \% both genders & \% men & \% women \\
\hline No & 58.8 & 64.9 & 54.9 \\
\hline Slightly & 35.3 & 33.8 & 36.3 \\
\hline Significantly & 5.9 & 1.4 & 8.8 \\
\hline Together & 100 & 100 & 100 \\
\hline
\end{tabular}

From the results shown in Table 7 it becomes apparent that almost $59 \%$ of parents did not change the rules for using media by their children during the lockdown. More than 1/3 of parents admitted that the lockdown has led them to slightly modify these rules. Only $6 \%$ of parents admitted significant changes in the rules. Gender-wise, the differences between men and women have been significant. Women more often admitted the need to change the rules. $45 \%$ of women admitted such changes, in contrast to just $34 \%$ of men. This could be related to the fact that the women more often stayed at home with their children, and therefore perceived the need to regulate the use of the media by the children.

\section{CONCLUSIONS}

Finally, the answer to the research question is "how the parents responded to the difficult situation and how they coped with the increased need for child care and regulation of children's media activities as well as the compensation of the unilateral load caused by media use". Our research has focused on the experience of the parents with supporting their children during the lockdown, chiefly regarding the children's use of the media.

The results of the research can be compared with the theoretical background presented in Part 2 of the article.

1. Research from various countries has shown that at least $50 \%$ of children use more media than usual during lockdown (Fisher, 2020). Our research has confirmed this trend. It is clear from Fig. 2 that according to $84 \%$ of parents, their children spent more time on electronic media during the lockdown. Only less than $16 \%$ of parents assume that their children spent the same or less time with electronic media during the 
spring lockdown than before. The increase in time spent in the media was mainly due to school education, but entertainment too.

2. The increase in children's time in the media has been confirmed. This fact was followed by questions about how parents cope with the situation that children spend more time with the media. It is possible to follow two different trends - repressive and preventive. The available research is dominated by the repressive solution that parents reduce the amount of time spent with the media during lockdown (Fisher, 2020).

In our research, this trend has not been fully confirmed. As Table 7 shows, almost $59 \%$ of parents did not change their children's media use rules during locking. About $1 / 3$ of the parents admitted that locking them led to a slight adjustment of these rules. Only $6 \%$ of parents admitted significant changes to the rules. The need to change the rules was accepted by more women than men. Women were more likely to stay at home with their children during the lockdown, so they were more aware of the need to change the rules for using the media.

3. During the lockdown, the parents tried to prevent the excessive use of the media by the children as well as preventive, active spending free time together with the children.

From the available research, it is clear that during the lockdown, families spend more time together. Joint activities of families are either physical and sports, or creative, cultural, handicraft. Families also spend time watching television or listening to music together (Goldschmidt, 2020).

Table 6 shows that joint outdoor activities predominated in our research $65 \%$ stay in the garden, $60 \%$ walks). Of the physical activities, cycling was often mentioned (27\%). Inside the home, families most often played board games together $(29 \%)$ or watched television $(25 \%)$.

4. Gender differences in parental mediation strategies, described by Duek and Moguillansky (2020) found that certain tasks were considered more typical for fathers and others were to be the domain of mothers.

Our research showed gender differences, especially in the adjustment of working conditions of parents at the time of lockdown. Table 4 shows that only about $4 \%$ of men remained at home during the lockdown, but $22 \%$ were women. Women also worked from the home office $(31 \%)$ more often than men (15\%). Almost half of the male respondents stated that they go to work as usual, while only $20 \%$ of women. On the contrary, there were slightly more men than women who reported working more than usual ( $8 \%$ of men and $3 \%$ of women).

More than half of the mothers claimed that they had more time for their children than usual. This number is probably related to the higher percentage of mothers who stayed at home with their children or worked from a home office. As for fathers, only $29 \%$ said they had more time between parents and children.

When comparing the results in terms of gender, more mothers than fathers are more active in the implementation of family leisure activities, as shown in Table 6.

Analysing the differences between the stances adopted by mothers and fathers, we can conclude that mothers acted as the main supporters and carers of their children. They more often stayed at home with their children, spending more time with them, supporting them more intensively in their on-line education. They also more often perceived the need to change the rules for using the media by the children.

Our result accord with previous surveys, which point on the still existing intensive role of women in upbringing and care of children in families. For example, our 2012 research (Stašová, Slaninová, Junová, $2015,151)$ has shown that women are rather important agents of the media education of their children. Older surveys from other countries have shown the same thing (e.g. Livingstone, 2007, Nathanson, Yang, 2003 at al.).

The pandemic and lockdown period turn out to be stressful for women in many respects, not only regarding the upbringing of children in their families. "The findings add further support to the call for preventive programs to support parents throughout the COVID-19 pandemic. Mental health professionals and social workers should be warned of the effects of lockdown and social distancing on parenting and, consequently, the well-being of children" (Marchetti, 2020). For comparison, was quote from the results provided by Caroll et al. (2020): „while parents expressed concern about the amount of screen time their children were getting, many parents also identified structural changes that made it challenging to limit their children's screen time such as using screens for children's online learning/schooling and the need to use screens to engage their children while they completed their paid work from home". The lockdown led to the expansion of time parents could be spending with their children. Yet at the same time, this expansion was demanding for the parents, introducing numerous duties and responsibilities. 
The family is still responsible for the children's activities, social contact, and experience, even under the extreme circumstances of the pandemic. The demands put on today's parents importantly include reflexivity, responsibility, creativity, and work with identity (see Faircloth, Hoffmann, Layne, 2013). To be a good parent means "to be engaged in the children's everyday life" (see Lareau, Weininger, 2008). This may be particularly demanding and exhausting during the lockdown. Not only the couples should therefore provide mutual help, but the whole society should support the parents in their role in the upbringing and care of their children under the exceptional circumstances.

\section{ACKNOWLEDGEMENTS}

This survey has been conducted as a part of a specific research at the Faculty of Education of the University of Hradec Králové.

\section{REFERENCE LIST}

Aanmari, T., Schoenbeck, S. (2018). Understanding and Supporting Fathers and Fatherhood on Social Media Sites. Conference: the 33rd Annual ACM Conference.

Caroll, N., et al. (2020). The Impact of COVID-19 on Health Behavior, Stress, Financial and Food Security among Middle to High Income Canadian Families with Young Children. Nutrients 2020, 12.

Duek, C., Moguillansky, M. (2020). Children, digital screens and family: parental mediation practices and gender. [online]. Comunicação e sociedade, 37. Available at: file:///C:/Users/notebook/Downloads/cs2362.pdf

Duggan, M. et al. (2015). Parents and Social Media. Pew Research Center.

Faircloth, Ch., Hoffman, D. M., Layne, L. L. (Eds.) (2013). Parenting in global perspective: negotiating ideologies of kinship, self and politics. London and New York: Routledge.

Fisher, S. (2020). Kids' daily screen time surges during coronavirus. [online]. Axios. Available at: https://www.axios.com/kids-screen-time-coronavirus-562073f6-0638-47f2-8ea3-4f8781d6b31b.html

Goldshmidt, K. (2020). The COVID-19 Pandemic: Technology use to Support the Wellbeing of Children. Journal of Pediatric Noursing, 53.

Lareau, A., Weininger, E. B. (2008). Time, Work, and Family Life: Reconceptualizing Gendered Time Patterns Through the Case of Children's Organized Activities. Sociological Forum. 23 (3).

Livingstone, S. (2007). Strategies of parental regulation in the mediarich home [online]. London: LSE Research Online. Available at: http://eprints.Ise.ac.uk/1019

Marchetti, D. et al. (2020). Parenting-Related Exhaustion During the Italian COVID-19 Lockdown. Journal of Pediatric Psychology, 45 (10).

Nathanson, A. I., Yang, M. S. (2003). The Effects of Mediation Content and Form on Children's Responses to Violent Television. Human Communication Research, 29 (1).

Pavlát, J. (2008). Děti, otcovství a rodina. Česká a slovenská psychiatrie, 104 (4).

Roskam, I., Raes, M. E., Mikolajzcak, M. (2017). Exhausted parents: Development and preliminary validation of the parental burnout inventory. Frontiers in Psychology, 8 (163).

Stašová, L., Slaninová, G., Junová, I. (2015). Nová generace: vybrané aspekty socializace a výchovy současných dětí a mládeže v kontextu medializované společnosti. Hradec Králové: Gaudeamus.

Tang, L. et al. (2018) Mothers' and fathers' media parenting practices associated with young children's screen-time: a cross-sectional study. BMC Obesity, 5 (37). https://doi.org/10.1186/s40608-018-0214-4

Torres, N., Veríssimo, M., Monteiro, L., Ribeiro, O., Santos, A. J. (2014). Domains of father involvement, social competence and problém behavior in preschool children. Journal of Family Studies, 20 (3).

Uhls, Y. T. (2018). Mediální mámy a digitální tátové. Praha: Portál.

Van Den Bulck, J., Van Den Bergh, B. (2000). The Influence of Perceived Parental Guidance Patterns on 
Childrens' Media Use: Gender Differences and Media Displacement. Journal of Broadcasting \& Electronic Media, 44 (3).

Yoder, J. R., Brisson D., Lopez, A. (2016). Moving Beyond Fatherhood Involvement: The Association Between Father-Child Relationship Quality and Youth Delinquency Trajectories. Family Relations, 65 (3). 